\title{
Analisis Biaya Produksi dalam Meningkatkan Volume Penjualan
}

\author{
Irfan Faris Rudiana1), Toto2), Dedi Rudiana3) \\ 1 Fakultas Ekonomi, Universitas Galuh \\ 2 Fakultas Ekonomi, Universitas Galuh \\ ${ }^{3}$ Fakultas Ekonomi dan Bisnis, Universitas Siliwangi
}

\begin{tabular}{l}
\hline ARTICLE INFO \\
\hline Article History: \\
Received Nov $14^{\text {th }}, 2020$ \\
Revised Aug $13^{\text {th }}, 2021$ \\
Accepted Aug $16^{\text {th }}, 2021$
\end{tabular}

Keywords:

Biaya Produksi;

Volume Penjualan.

\begin{abstract}
The company requires production costs in every run of its operational activities. Production costs are used to process raw materials or semi-finished goods into finished products. The cost of raw materials, labor costs, and factory overhead costs become the main components in the formation of costs will determine the cost of production and the price of goods sold (HPP). Production costs are all costs associated with the goods produced, in which there is an element of raw material costs, labor costs, and factory overhead costs. The purpose of this study was to analyze: 1) Identification of the types of costs - costs in the business of lovebird cattle in Tasikmalaya and 2) determine the effect of production costs in increasing sales volume. The method used is a survey method with quantitative and qualitative approaches. The quantitative approach analyzes the effect of production costs on sales volume, while the qualitative approach to identify the types of costs used in lovebird livestock businesses in Tasikmalaya. The types of data collected are primary data and secondary data, with data collection techniques being documentation and interviews while the technique of analysis with descriptive analysis. Based on the results of the simple regression $t$-test obtained a significance value of 0.055 . Where $0.055>$ 0.05 means that the production cost at each farm has an almost significant effect on the sales volume of lovebirds.
\end{abstract}

Perusahaan memerlukan biaya produksi dalam setiap menjalankan kegiatan operasionalnya. Biaya produksi digunakan untuk mengolah bahan baku atau barang setengah jadi menjadi produk jadi. Biaya bahan baku, biaya tenaga kerja, dan biaya overhead pabrik menjadi komponen utama dalam pembentukan biaya akan menentukan harga pokok produksi dan harga pokok penjualan (HPP). Menurut M. Nafarin (2009:497) Biaya produksi adalah seluruh biaya yang berhubungan dengan barang yang dihasilkan, dimana didalamnya terdapat unsur biaya bahan baku, biaya tenaga kerja, dan biaya overhead pabrik. Tujuan penelitian ini untuk menganalisis: 1) Identifikasi jenis biaya - biaya dalam usaha ternak lovebird di tasikmalaya dan 2) menentukan pengaruh biaya produksi dalam meningkatkan volume penjualan. Metode yang digunakan adalah metode survei dengan pendekatan kuantitatif dan kualitatif. Pendekatan kuantitatif untuk menganalisis pengaruh biaya produksi terhadap volume penjualan, sedangkan pendekatan kualitatif untuk mengidentifikasi jenis biaya - biaya yang digunakan dalam usaha ternak lovebird di Tasikmalaya. Jenis data yang dikumpulkan adalah data primer dan data sekunder, dengan teknik pengumpulan data dokumentasi dan wawancara sedangkan teknik analisis dengan deskriptif analisis. Berdasarkan hasil uji t regresi sederhana diperoleh nilai signifikansi sebesar 0,055. Dimana 0,055 >0,05 ini mempunyai arti bahwa biaya produksi pada setiap farm berpengaruh hampir signifikan terhadap volume penjualan lovebird.

How to Cite: Rudiana, I.F., Toto., Rudiana, D.(2021).Analisis biaya produksi dalam meningkatkan volume penjualan. Sosio e-Kons, 13 (02), 82-86. http://dx.doi.org/10.30998/sosioekons.v13i2.7866 


\section{PENDAHULUAN}

Peternak burung khususnya lovebird di tasikmalaya diharapkan lebih mampu untuk menganalisis biaya - biaya yang bisa berpengaruh besar terhadap produktivitas dan angka kematian indukan burung lovebird, peternak juga diharapkan mampu mengidentifikasi jenis biaya - biaya yang digunakan dalam beternak lovebird. Menurut Nafarin (2009:497) biaya produksi adalah seluruh biaya yang berhubungan dengan barang yang dihasilkan, dimana didalamnya terdapat unsur biaya bahan baku, biaya tenaga kerja langsung, dan biaya overhead pabrik. Dimana dalam hal ini yang termasuk biaya bahan baku yaitu indukan lovebird, biaya tenaga kerja langsung yaitu biaya keeper burung lovebird, dan biaya overhead pabrik disini adalah biaya obat - obatan, biaya listrik mesin penetas telur lovebird dan inkubator anakan burung lovebird.

Dengan adanya pengidentifikasian biaya pada usaha ternak lovebird diharapkan semua peternak khususnya di Tasikmalaya mampu untuk meminimalisasi kerugian dan risiko kematian serta bisa meningkatkan volume penjualan. Menurut penelitian Nusa, dkk (2009) dalam melakukan operasi bisnis perusahaan dapat dikatakan berhasil apabila dari masa ke masa dapat mengumpulkan keuntungan dengan meningkatkan penjualan dan kemampulabaan yang memadai.

Menurut www.lovebirdindonesia.com pada tahun 2017 harga burung lovebird jenis warna parblue memilik harga yang fantastis dan tak masuk akal, satu ekor burung rata - rata bisa mencapai Rp 75.000.000, seiring dengan bertambahnya peternak lovebird di Indonesia maka harga lovebird pun menurun drastis, hingga pada tahun 2019 ini harga lovebird warna parblue memiliki harga Rp 2.000.000 - Rp 4.500.000 per ekor. Mengingat pentingnya pengidentifikasian biaya dan pengaruh biaya produksi terhadap volume penjualan burung lovebird, maka peneliti akan melakukan penelitian dengan tema "Analisis Biaya Produksi dalam Meningkatkan Volume Penjualan" pada peternak lovebird di Tasikmalaya.

Berdasarkan latar belakang penelitian di atas, maka peneliti merumuskan permasalah dalam bentuk pertanyaan penelitian sebagai berikut (1) Bagaimana identifikasi biaya produksi pada peternak burung lovebird di Tasikmalaya? (2) Bagaimana pengaruh biaya produksi terhadap volume penjualan pada peternak burung lovebird di Tasikmalaya?. Kemudian berdasarkan perumusan masalah di atas, maka tujuan dari penelitian ini adalah untuk : (1) Mengidentifikasi biaya produksi pada peternak burung lovebird di Tasikmalaya, (2) Menganalisis pengaruh biaya produksi terhadap volume penjualan pada peternak burung lovebird di Tasikmalaya

\section{METODE}

Metode penelitian yang digunakan adalah metode deskriptif dengan pendekatan kuantitatif. Tujuan penggunaan metode tersebut adalah untuk menggambarkan fenomena atau karakteristik terhadap data selama penelitian berlangsung dan untuk menguji dan menjawab pertanyaan penelitian. Penelitian ini dilakukan pada peternak burung lovebird di Tasikmalaya sebagai peternak yang berskala besar, dan mencatat segala biaya yang dipakai selama produksi. Fokus pada penelitian ini adalah mengidentifikasi segala jenis biaya dan mencari pengaruh biaya produksi terhadap volume penjualan. Berikut peneliti lampirkan alur dari metode penelitian ini :

1. Tahap Pendahuluan

Tahap awal adalah penyusunan pendahuluan yang berisi latar belakang penelitian untuk menjelaskan permasalahan yang terkait dengan biaya produksi pada peternak lovebird di Tasikmalaya. Semantara itu tujuan khusus merupakan tujuan yang hendak dicapai dalam penelitian ini, yaitu untuk menganalisis pengaruh biaya produksi terhadap volume penjualan dan mengidentifikasi jenis - jenis biaya pada peternak burung lovebird di Tasikmalaya. Selanjutnya adalah penyusunan kajian pustaka, yang berisi state of the art dan roadmap penelitian. Teori-teori merupakan teori yang diambil dari sumber-sumber seperti jurnal dan buku. Teori-teori yang 
digunakan adalah teori yang relevan dengan penelitian ini. Berikutnya menyusun metode penelitian. Metode yang digunakan adalah metode survei dengan pendekatan kuantitatif dan kualitatif. Pendekatan kuantitatif adalah untuk menganalisis pengaruh biaya produksi terhadap volume penjualan. Sedangkan pendekatan kualitatif adalah untuk mengidentifikasi jenis - jenis biaya pada peternak burung lovebird di Tasikmalaya. Teknik analisis data adalah dengan menggunakan teknik deskriptif analisis.

2. Tahap Inventarisasi Data

Tahap inventarisasi data adalah tahap pengumpulan data penelitian, baik berupa data sekunder maupun data primer yang dibutuhkan dalam penelitian ini. Data sekunder berupa laporan keuangan peternak burung lovebird di Tasikmalaya, sedangkan data primer berupa wawancara mendalam dengan informan.

3. Tahap Analisis

Sebelum dianalisis data terlebih dahulu diidentifikasi agar data-data dapat dipilih sesuai dengan kebutuhan penelitian. Setelah itu data dianalisis untuk menjawab pertanyaan penelitian. data yang telah dianalisis dituangkan dalam pembahasan hasil penelitian.

4. Tahap Finalisasi

Pada tahap akhir adalah penyusunan pembahasan penelitian. Pembahasan penelitian adalah menguraikan temuan-temuan yang diperoleh selama proses penelitian berlangsung. Setelah itu hasil dari penelitian disimpulkan dan memberikan saran-saran yang sekiranya diperlukan untuk lebih mengoptimalkan produksi pada peternak lovebird di Tasikmalaya.

\section{HASIL DAN PEMBAHASAN}

\section{Identifikasi Biaya Produksi Pada Peternak Lovebird di Tasikmalaya}

Identifkasi biaya ini memiliki peranan yang sangat penting untuk mengetahui unsur apa saja yang membutuhkan pendanaan serta besaran biaya yang disebutkan. Biaya produksi pada peternak lovebird di Tasikmalaya tersaji pada gambar 1 .

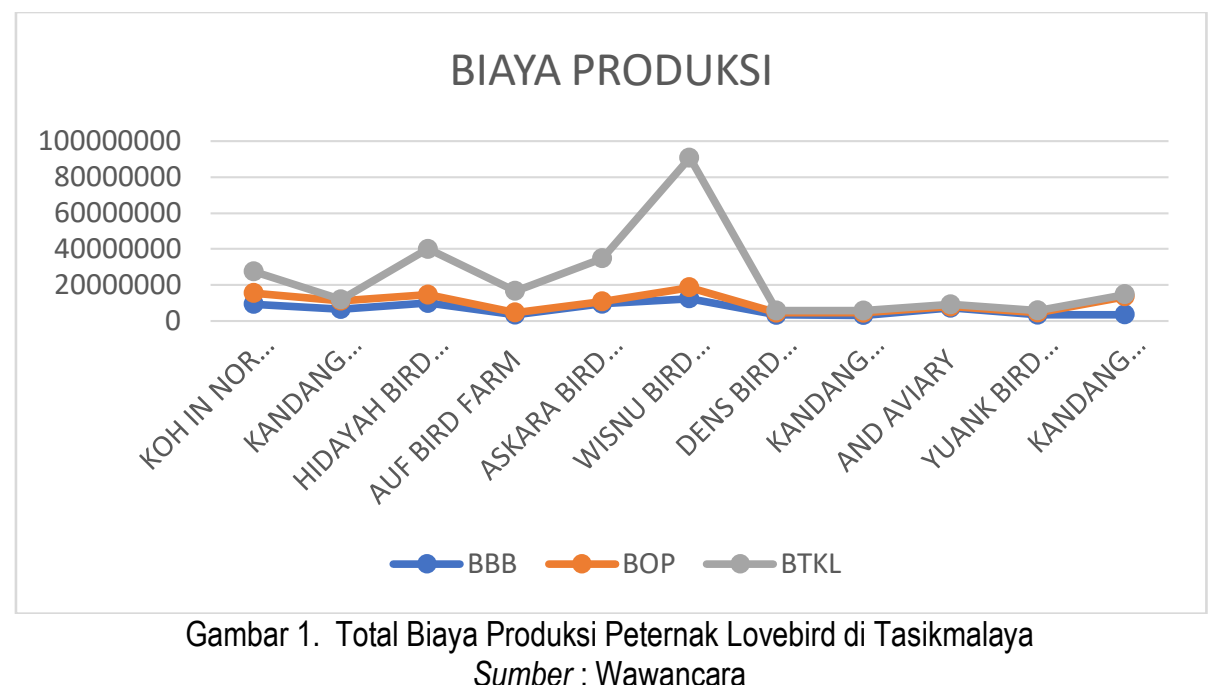

Gambar 1. menyajikan total biaya produksi pada peternak lovebird yang ada di Tasikmalaya. Dilihat dari gambar sudah bisa disimpulkan bahwa biaya produksi setiap farm itu berbeda-beda tergantung kebutuhan dan volume produksi yang dimiliki. Terlihat yang memiliki Biaya Tenaga Kerja Langsung paling tinggi yaitu Wisnu Bird Farm dimana di farm ini memiliki karyawan 5 orang, memiliki lebih dari 50 pasang Lovebird dan mempunyai biaya overhead yang paling tinggi. Biaya bahan baku 
Wisnu bird farm juga terlihat lebih tinggi. Biaya produksi meliputi Biaya Bahan Baku (BBB), Biaya Overhead pabrik (BOP) dan Biaya Tenaga Kerja Langsung (BTKL)

\section{Volume Penjualan Pada Peternak Lovebird di Tasikmalaya}

Volume penjualan Lovebird pada peternak Lovebird di Tasikmalaya tersaji pada gambar 2.

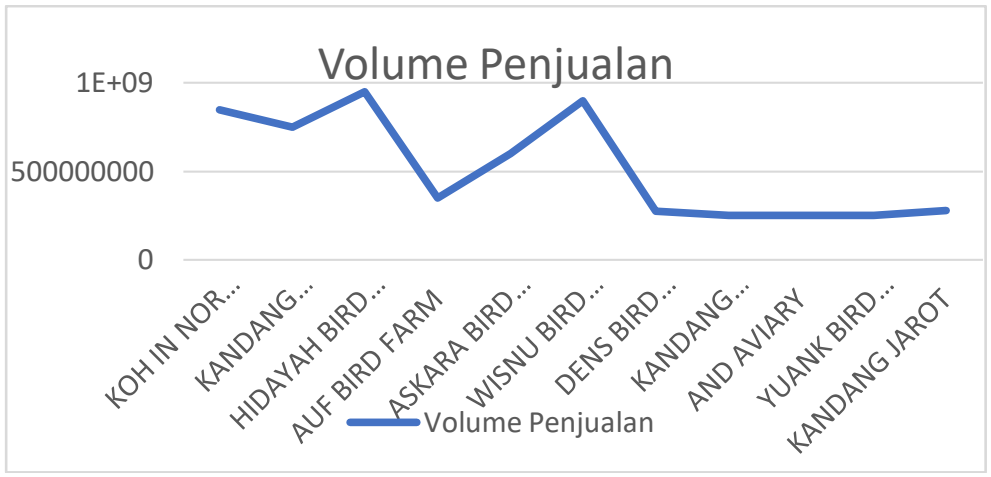

Gambar 2. menyajikan rata-rata total volume penjualan lovebird pada peternak lovebird di Tasikmalaya. Terlihat yang mempunyai volume penjualan terbesar yaitu Hidayah Bird Farm. Dengan total penjualan yaitu sebesar Rp 950.000.000,- dan volume penjualan terkecil yaitu Kandang Borneo dan Yuank Bird Farm sebesar Rp 250.000.000,-

\section{Perbandingan Biaya Produksi dan Volume Penjualan Pada Peternak Lovebird di Tasikmalaya}

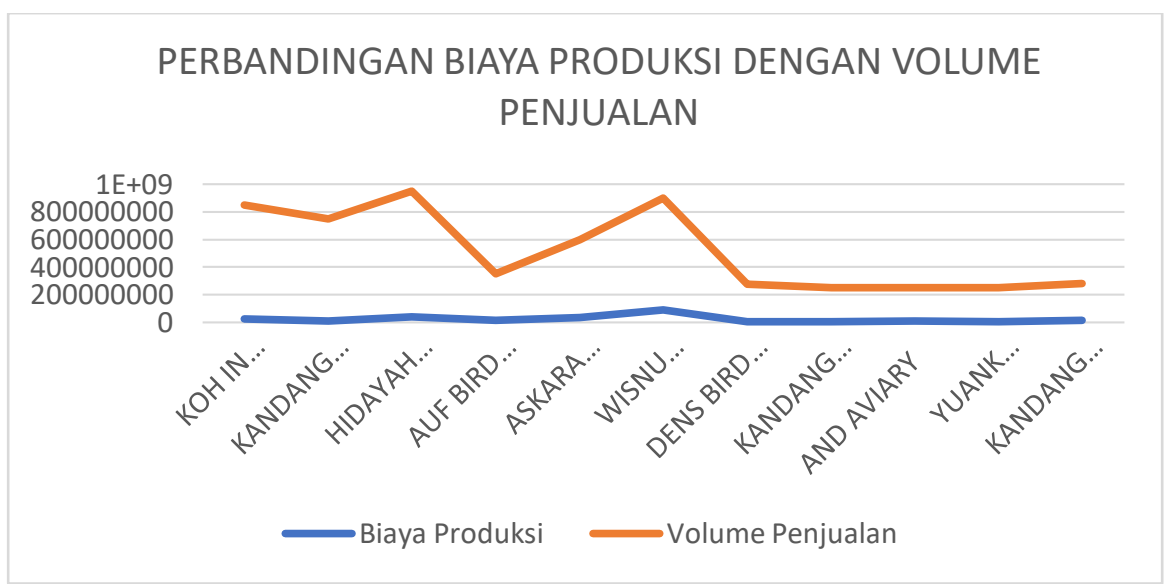

Gambar 3. menyajikan perbandingan biaya produksi dengan volume penjualan pada peternak lovebird di Tasikmalaya pada satu tahun terakhir yaitu tahun 2019. 11 Peternak Lovebird ini dijadikan sample karena menurut profil bisnis, usaha mikro, kecil dan menengah (UMKM) yang terdapat pada www.bi.go.id masuk UMKM Menengah yang mempunyai aset antara 500 juta sampai dengan 10 Milliar dengan omset Rp. 2,5 Milliar sampai dengan 10 Milliar. Berdasarkan hasil uji statistik dengan menggunakan regresi sederhana, didapat persamaan $Y=-4085114,663+0,050 x+e$, dimana berdasarkan hasil uji $t$ diperoleh nilai signifikansi sebesar 0,055 . Dimana $0,055>0,05$ ini mempunyai arti bahwa biaya produksi berpengaruh hampir signifikan terhadap volume penjualan. Hasil ini sejalan dengan penelitian Putu Rustami dkk (2014) biaya produksi berpengaruh terhadap laba penjualan pada perusahaaan kopi bubuk banyu atis singaraja. Biaya produksi yang tinggi dan berbeda diakibatkan dari beberapa faktor, diantaranya ialah jumlah kandang yang dimiliki setiap farm berbeda, sehingga biaya pakan, biaya obat-obatan, biaya overhead yang meliputi biaya listrik mesin penetas, mesin inkubator juga berbeda. Tak hanya itu Biaya Tenaga Kerja Langsung atau upah karyawan pun berbeda diakibatkan karena setiap farm mempunyai jumlah karyawan yang berbeda. 
Berbagai trik yang dilakukan oleh para peternak lovebird untuk meningkatkan volume penjualan lovebird di Tasikmalaya, selain itu peternak juga mencari berbagai cara untuk mencegah pembengkakan biaya produksi, antara lain dengan memberikan obat -obatan yang berkualitas agar meminimalisasi resiko kematian anak, dan meminimalisasi kematian indukan disaat pergantian musim. Upaya - upaya yang dilakukan oleh peternak lovebird terus dilakukan agar gairah lovebird di Indonesia semakin meningkat, seminar mengenai teori SexLinked Lovebird, dan berbagai macam rekayasa genetika terus ditekankan agar bisa mencetak lovebird dengan morph yang variatif.

\section{SIMPULAN DAN SARAN}

Biaya Produksi pada peternak lovebird di Tasikmalaya mempunyai biaya bahan baku, biaya overhead pabrik dan biaya tenaga kerja langsung untuk menjalankan kegiatan operasionalnya dalam menentukkan harga pokok produksi dalam hal ini yaitu harga per ekor burung lovebird. Berdasarkan hasil uji $t$ regresi sederhana diperoleh nilai signifikansi sebesar 0,055. Dimana 0,055>0,05 ini mempunyai arti bahwa biaya produksi pada setiap farm berpengaruh hampir signifikan terhadap volume penjualan lovebird. Selain itu banyak faktor lain untuk meningkatkan volume penjualan lovebird di Indonesia salah satunya adalah dengan membuat ring atau gelang untuk dipasangkan di kaki anakan lovebird ini, hasil anakan yang dihasilkan dari setiap farm di kakinya mempunyai ring dengan nama farm dan nomor handphone peternak nya sebagai identitas. Selain itu silaturahmi antarkomunitas dan mempunyai indukan yang berkualitas juga merupakan salah satu faktor meningkatkan volume penjualan, indukan berkualitas akan melahirkan anakan yang berkualitas, anakan berkualitas tersebut akan cepat laku diburu oleh konsumen baik konsumen di Tasikmalaya ataupun di luar Tasikmalaya.

\section{REFERENSI/DAFTAR RUJUKAN}

Asep Mulyana (2017). Pengaruh Biaya Produksi dan Biaya Promosi Terhadap Laba Usaha Samsung Co pada Tahun 2009-2015

Budiastuti (2016). Pengaruh Volume Penjualan dan Biaya Produksi Terhadap Laba Bersih Pada PT. Indah Kiat Pulp and Paper Tbk 2006-2015

Kuswadi. (2005). Meningkatkan Laba Melalui Pendekatan Akuntansi Keuangan dan Akuntansi Biaya. PT. Elex Media Komputindo, Jakarta.

M.Nafarin.(2009). Penganggaran Perusahaan. Penerbit Salemba 4. Jakarta Mulyadi. (2015). Akuntansi Biaya, Edisi5. Yogyakarta: Sekolah Tinggi Ilmu Manajemen YKPN.

Nusa, Muktiadji (2009) Analisis Pengaruh Biaya Produksi dalam Peningkatan Kemampulabaan Perusahaan, Studi Kasus Pada PT HM Sampoerna. Jurnal IImiah Kesatuan Nomor 1 Volume 11, Januari 2009.

Rangkuti, Freddy.(2009). Strategi Promosi yang Kreatif dan Analisis KasusIntegrated Marketing Communication. Jakarta : PT. GramediaPustakaUtama

Sukirno, Sadono. (2013). Makroekonomi : Teori Pengantar. Jakarta : PT. Raja Grafindo Persada www.lovebirdindonesia.com

Yuma, A dkk. (2006). Pengaruh Biaya Produksi Terhadap Volume Penjualan. Pada PT Kertas Padalarang 